\title{
Evaluation of tissue metalloproteinase inhibitor TIMP-1 and Survivin levels during third trimester pregnancy a preliminary report
}

Agata Karowicz-Bilińska, Urszula Kowalska-Koprek, Dorota Estemberg, Anita Sikora-Szubert

High Risk Pregnancy Unit, $1^{\text {st }}$ Department of Obstetrics and Gynecology Medical University of Lodz, Poland

\begin{abstract}
Objectives: A proper implantation of trophoblastic cells and an appropriate metalloproteinases activity is required to cause disintegration of basal membranes of cells. The activity of tissue matrix metaloproteinases can be inhibited by their matrix inhibitors - TIMP-s. Survivin is a member of inhibitor of apoptosis proteins family (IAP), that suppresses caspase activation, influences VEGF expression and promotes proliferative action of endothelial cells.

Material and methods: The aim of the study was to assess concentrations of two independent anti-apoptotic factors. TIMP-1 and survivin in serum of women in their third trimester of pregnancy and in umbilical cord blood of neonates - drawn separately from veins and arteries. The study group consisted of 29 pregnant women in physiological pregnancy and with correct fetal development, in gestational age between 37 to 40 weeks of gestation. Blood used in the study was collected from maternal cubital fossa veins and from neonatal umbilical cords (from veins and from arteries separately). The research was conducted using TIMP-1 and Survivin ELISA kits from R \& D Systems according to manufacturers' recommendations and protocols.

Results: The concentrations of TIMP-1 were similar and independent of the source of blood samples. Arterial values of TIMP-1 in umbilical cord compared to maternal and fetal veins were slightly lower, but no statistical difference was found. The mean concentrations of Survivin were comparable but we found that in some cases the results in cord blood serum in both vessels-vein and arteries were almost negative. Arterial values of Survivin in umbilical cord compared to maternal blood were higher, but no statistical difference was found.

Conclusions: In III-rd trimester of pregnancy parameters of Timp-1 and Survivin — anti-apoptotic substances concentration were similar in maternal and cord blood in both artery and vein. We found no increased activity of selected antiapoptotic factors.
\end{abstract}

Key words: pregnancy, umbilical cord blood, TIMP-1, Survivin

\section{INTRODUCTION}

Fetal development in physiological pregnancy depends on many external and internal factors. One of the most important factors is a proper trophoblast implantation that ensures proper placental function later in pregnancy and therefore correct fetal development.

Common complications caused by an incorrect implantation may include pregnancy induced hypertension and intrauterine fetal growth restriction.
Among many factors determining successful trophoblast implantation, alterations in extracellular matrix structure and the disintegration of basal membranes of cells play a crucial role. Those phenomena are a result of matrix metalloproteinase activity and are determined by the presence of zinc particle in their enzymatic center. Structural and regulative functions of extracellular matrix are associated with the presence of proteins and polysaccharides from which they are composed [1, 2]. 
Metalloproteinase (MMP) family is involved in down regulation of organism's development, homeostasis, healing, reconstruction of tissues and angiogenesis.

MMPs are stimulated by cytokines as a result of organisms'reaction to inflammatory processes or cell damage [3].

Metalloproteinase activation begins with a detachment of pro-peptides and an exposure of the enzymatic center in the presence of other activated metalloproteinases or serine proteases and by altering the special structure of the metalloproteinase active center through a reaction with SH group [4].

Metalloproteinase activation results in an increased cytokine release and subsequent intracellular matrix collagen degradation allowing a leucocyte penetration to the inflammatory sources and inflammatory process restriction [5].

The biological action of metaloproteinases is regulated through different interactions with proteolytic enzymes inhibitors and specific inhibitors - tissue metalloproteinase inhibitors [TIMP]. Among the four well known tissue metalloproteinases inhibitors, TIMP-1 shows strong blocking action on MMP-1 and MMP-9, and a slightly weaker effect on MMP-2.

In addition to the effect of TIMP on the activity of other metalloproteinases, it also exhibits anti-apoptotic and pro-proliferative action in organogenesis [6].

Metalloproteinase and their specific inhibitors - TIMP create a proteolytic system that constructs a sensitive balance. If perturbed, it leads to an increased extracellular matrix decomposition and other proteolytic reactions in the process of placental implantation and placental angiogenesis.

Swierczewski found lower expression of one the TIMP markers [TIMP-2] in a group of healthy pregnant patients comparing to the group of IUGR [7].

Survivin is the smallest protein of anti-apoptotic effect (IAP- inhibitor of apoptosis protein), that inhibits caspase activation. It has been confirmed that the inhibition of Survivin activation path leads to an increase of apoptosis which in neoplastic disorders could retard hyperplasia.

Presence of Survivin was not only found in neoplastic cells but also in embryonic cells. In mature cells no expression of Survivin was found. Its activity probably dependent on p53 protein is observed at G2 stage of cell cycle, acting as a down regulator of mitotic processes by affecting tubulin [8]. As shown by Tamm, Survivin decreases two paths of apoptosis-through Bax and through Fas [9]. Among the known Survivin isoforms, variant-2 causes an increase of angiogenesis process. Survivin affects VEGF expression and promotes endothelial cells proliferation [10].

Control of apoptotic processes seems to be a main mechanism responsible for immune-suppression in pregnancy. Mediators of pro-apoptotic action released from placenta may cause T- lymphocytes apoptosis. An increase in the number of apoptotic leucocytes cohort [cd95+] in pregnant women compared to non-pregnant women confirms this observation.

Survivin plays a regulatory role in the development of placenta by controlling mechanisms of proliferation, apoptosis, angiogenesis, cell cycle control and trophoblast invasion [11]. Deregulation of these processes presumably leads to placental function disturbances and is associated with various pregnancy complications. Different matrix metaloproteinases (MMPs), their inhibitors and Survivin can affect the trophoblast implantation process and later placental function.

\section{OBJECTIVES}

The main aim of the study was to evaluate concentrations of two independent antiapoptotic factors-TIMP-1 and Survivin in serum of pregnant women in the third trimester of pregnancy and in umbilical cord blood of neonates.

\section{MATERIAL AND METHOD}

The study was conducted in High Risk Pregnancy Unit Medical University Lodz in 2013-2015 with the consent of the University Bioethics Board (RNN/149/09/KE).

The study group consisted of 29 pregnant women in physiological pregnancy and normal fetal development. Pregnancy age ranged between 37 to 40 weeks of gestation. Gestational age was estimated using the date of the last menstrual period and an early antenatal ultrasound. All of the patients delivered by elective caesarian section due to non-perinatal indications.

Vein blood was collected 2 to 4 hours before the planned caesarian section from cubital fossa veins and from umbilical cord separately from vein and from arteries after a neonate was separated from placental part of umbilical cord. The volume of all blood samples was no less than $5 \mathrm{~mL}$ each. The samples were placed in tubes without anticoagulants and stored in room temperature for about 60 minutes - to complete coagulation. When the clot was fully formed, samples were centrifuged for 15 minutes at 2000 rpm. After centrifugation blood samples were then placed into Eppendorf tubes, frozen and stored at $-70^{\circ} \mathrm{C}$ until the assay procedure.

The research was carried out using TIMP-1 and Survivin ELISA kits from R\&D Systems according to the manufacturer's recommendations. The minimum detectable dose (MDD) of TIMP-1 ranged from 87 to $524 \mathrm{ng} / \mathrm{mL}$. The sensitivity was $0.08 \mathrm{ng} / \mathrm{mL}$. The serum concentration of TIMP-1 was expressed in $\mathrm{ng} / \mathrm{mL}$. Survivin Assay Range was from $31.2-2.000 \mathrm{pg} / \mathrm{mL}$ and the sensitivity was $9.96 \mathrm{pg} / \mathrm{mL}$. Concentration of survivin was expressed in $\mathrm{pg} / \mathrm{mL}$.

\section{Statistical analysis}

Statistical data was prepared on calculation spreadsheet program Microsoft Excel 2014 and the calculations were 
done using SPSS 14.0 and MS Excel 2014. In the analyzed group for the individual results of measured parameters such as arithmetic mean, standard deviation, maximal and minimal values were indicated. Statistical analysis was performed using analysis of variance ANOVA. $P<0.05$ was the indicator of statistically significant difference.

The study group consisted of 29 healthy pregnant women in III-rd trimester of pregnancy. Mean age of the group was 32.17 (sd 3.83) years, minimal age was 25 years and maximal 38 years. The shortest gestational age was 37 weeks, the longest was 40 weeks. Mean pregnancy age was 38.7 weeks (sd 0.65).

\section{RESULTS}

In study group concentration of TIMP-1 was measured in maternal blood serum and in umbilical cord after delivery, separately for arterial and vein blood serum. The results are presented in $\mathrm{ng} / \mathrm{mL}$ on the graphs below.

The concentration of TIMP-1 in human serum due to producer's suggestion was from 87 to $524 \mathrm{ng} / \mathrm{mL}$. Figure 1 presented TIMP-1 concentration in maternal vein blood in group of pregnant women.
The highest TIMP-1 concentration was $429 \mathrm{ng} / \mathrm{mL}$ the lowest $158.9 \mathrm{ng} / \mathrm{mL}$. Mean value of TIMP-1 in maternal blood samples was $234.74 \mathrm{ng} / \mathrm{mL}$ (sd. 70.2).

Results of TIMP-1 concentration in artery of umbilical cord are presented in Figure 2.

The highest TIMP-1 concentration in umbilical cord artery serum was $395.8 \mathrm{ng} / \mathrm{mL}$ the lowest $110.3 \mathrm{ng} / \mathrm{mL}$. Mean value of TIMP-1 in maternal blood samples was $266.823 \mathrm{ng} / \mathrm{mL}$ (sd. 67.9).

The results of TIMP-1 concentration in umbilical cord vein blood is presented in Figure 3 .

The highest TIMP-1 concentration in umbilical cord vein serum was $426.9 \mathrm{ng} / \mathrm{mL}$ the lowest $208.1 \mathrm{ng} / \mathrm{mL}$. Mean value of TIMP-1 in maternal blood samples was $297.8 \mathrm{ng} / \mathrm{mL}$ (sd. 63.5).

The results obtained from maternal blood and cord blood were compared and presented in Figure 4.

By comparing differences betveen TIMP-1 plasma concentrations from maternal blood and umbilical cord blood from arteries and vein done by ANOVA variancy analysis showed no statistical differences.

Post-hoc analysis shows again no statistical differences betveen compared samples of TIMP-1 ( $p>0.05)$.

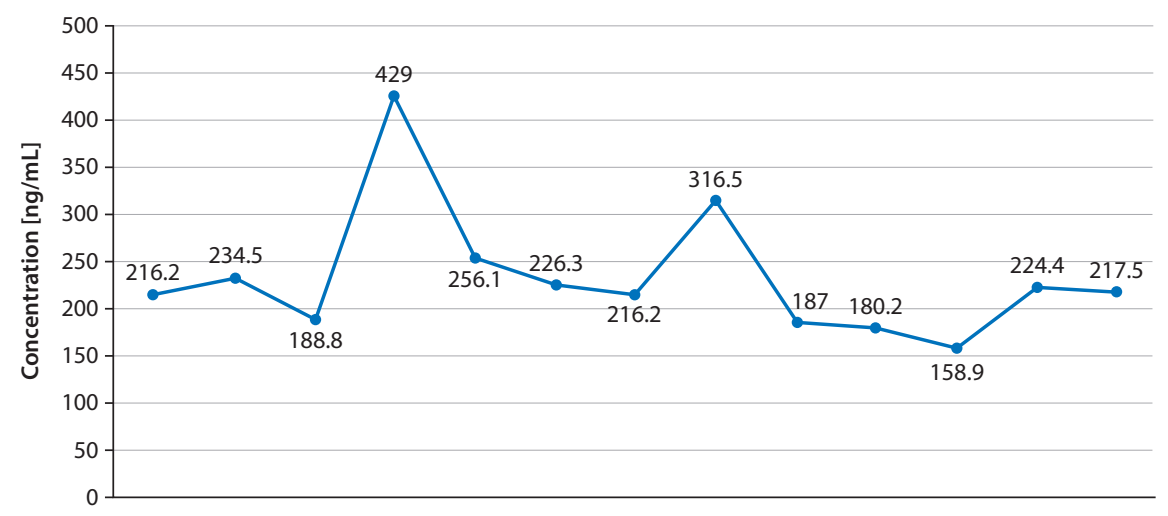

Figure 1. TIMP-1 concentration in maternal vein blood serum measured in $\mathrm{ng} / \mathrm{mL}$

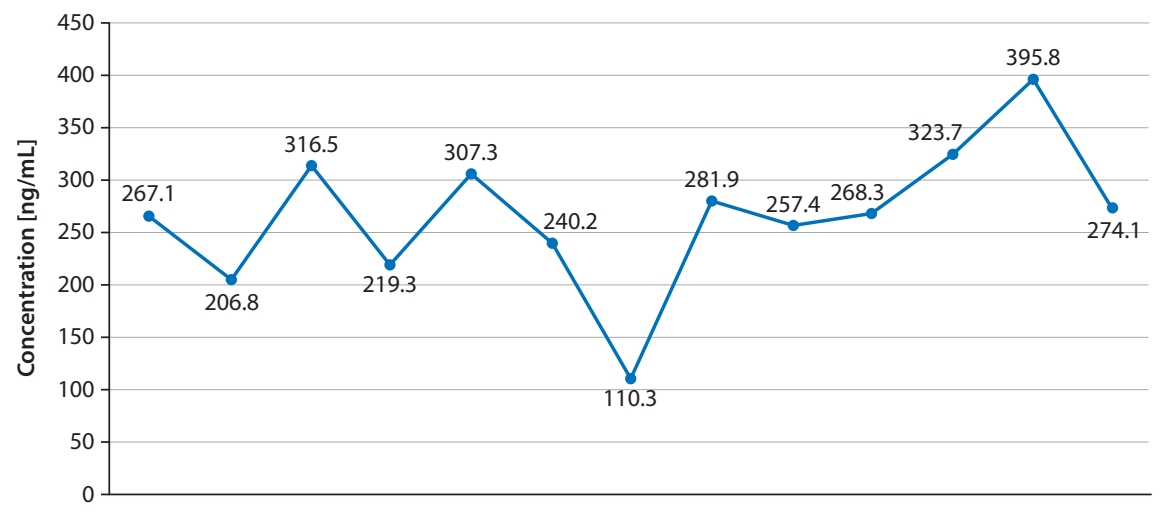

Figure 2. TIMP-1 concentration in arterial umbilical cord blood serum measured in $\mathrm{ng} / \mathrm{mL}$ 


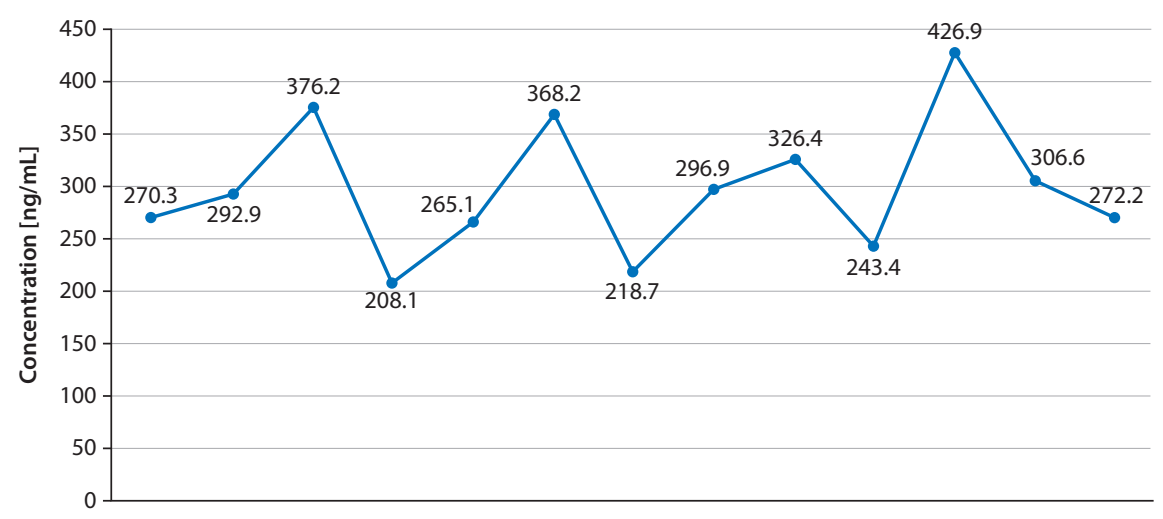

Figure 3. TIMP-1 concentration in vein umbilical cord blood serum measured in $\mathrm{ng} / \mathrm{mL}$

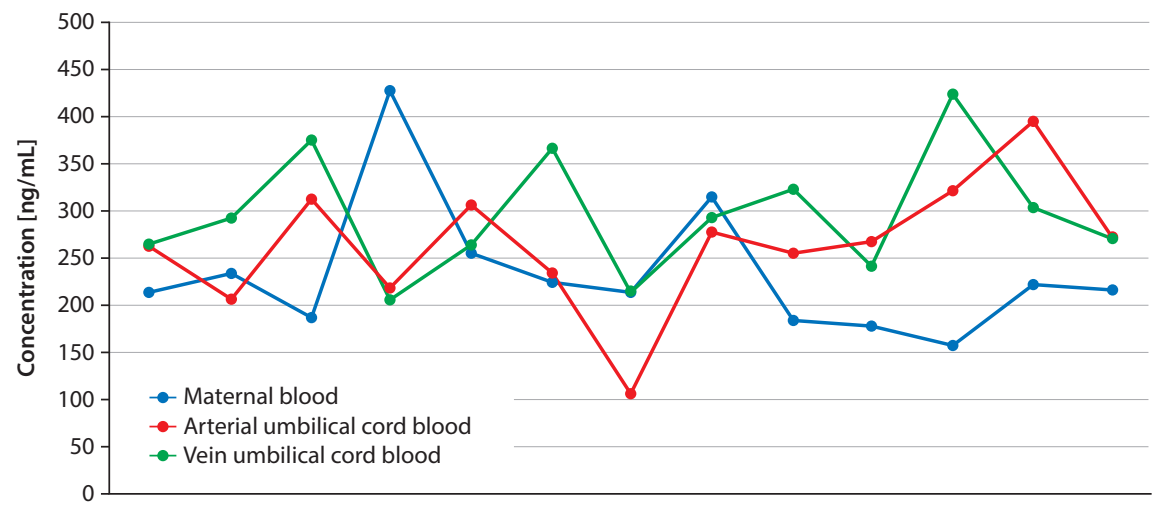

Figure 4. TIMP-1 concentration in compared blood samples

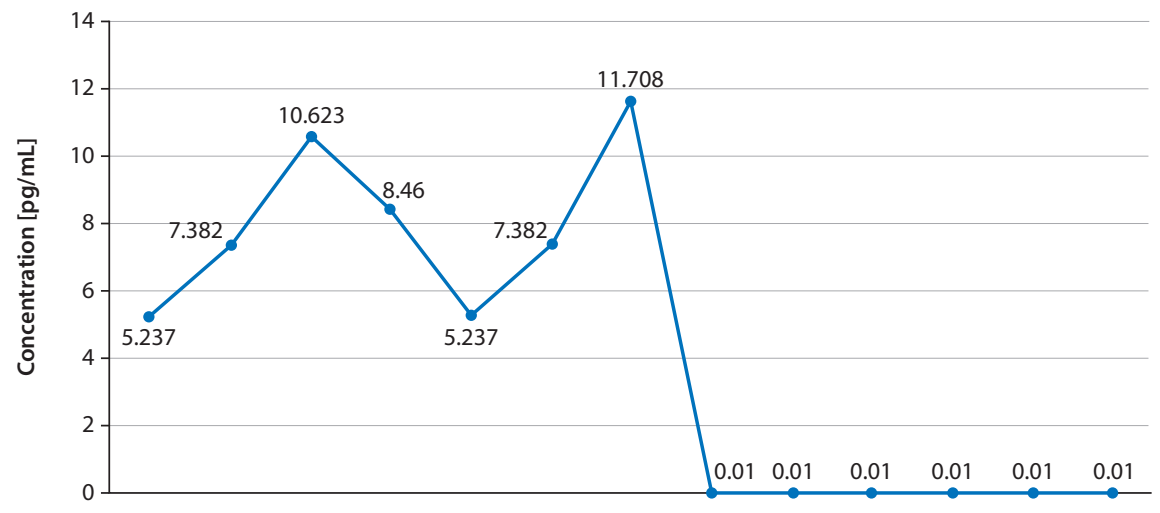

Figure 5. Survivin concentration in maternal blood serum in $\mathrm{pg} / \mathrm{mL}$

The concentrations of TIMP- 1 were similar and independent from the kind of blood vessels. Arterial values of TIMP-1 in umbilical cord compared to maternal and fetal veins were lower, but no statistical difference was found.

Presence of Survivin was found in embryonic cells and could be present in blood that contains fetal stem cells. Survivin concentration was measured in serum of maternal vein blood and umbilical cord blood separately for vein and arteries. The results of Survivin values in $\mathrm{pg} / \mathrm{ml}$ is presented in Figures 5-8.
The highest Survivin concentration in maternal vein serum was $11.708 \mathrm{pg} / \mathrm{mL}$, in 6 cases the results were nearly negative. Mean value of Survivin was $4.31 \mathrm{pg} / \mathrm{mL}$ (sd. 4.5).

The results obtained from umbilical cord arterial blood are presented in Figure 6.

The highest Survivin concentration from umbilical cord artery serum was $64.98 \mathrm{pg} / \mathrm{mL}$, in 6 cases the results in maternal blood were nearly negative, we found positive results from 34.80 to 1.01 . Only in one case the result was nearly 0. Mean value of Survivin was $14.03 \mathrm{pg} / \mathrm{mL}$ (sd. 17.5). 


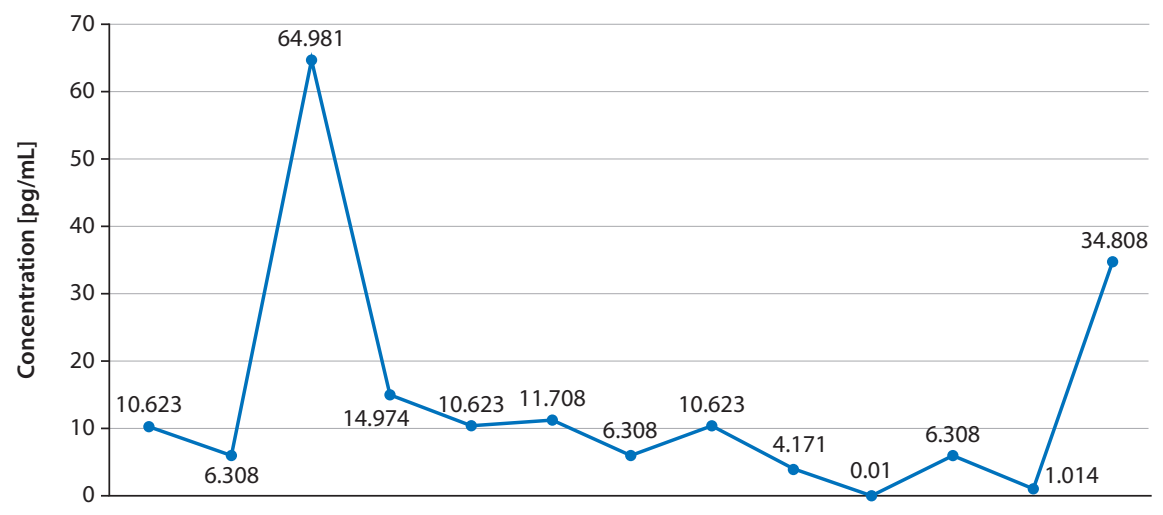

Figure 6. Survivin concentration in arterial umbilical cord blood plasma in $\mathrm{pg} / \mathrm{mL}$

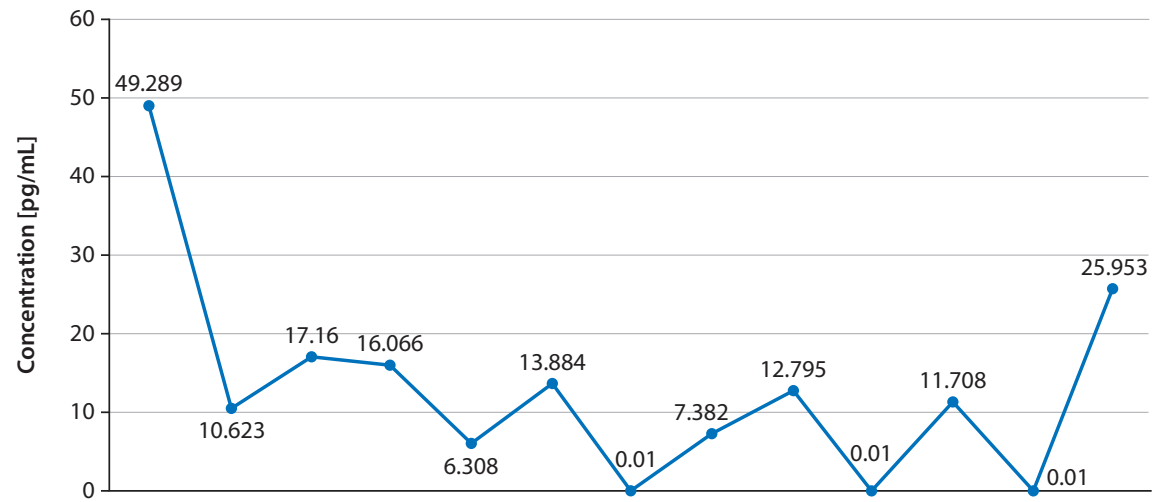

Figure 7. Survivin concentration in vein umbilical cord blood in $\mathrm{pg} / \mathrm{mL}$

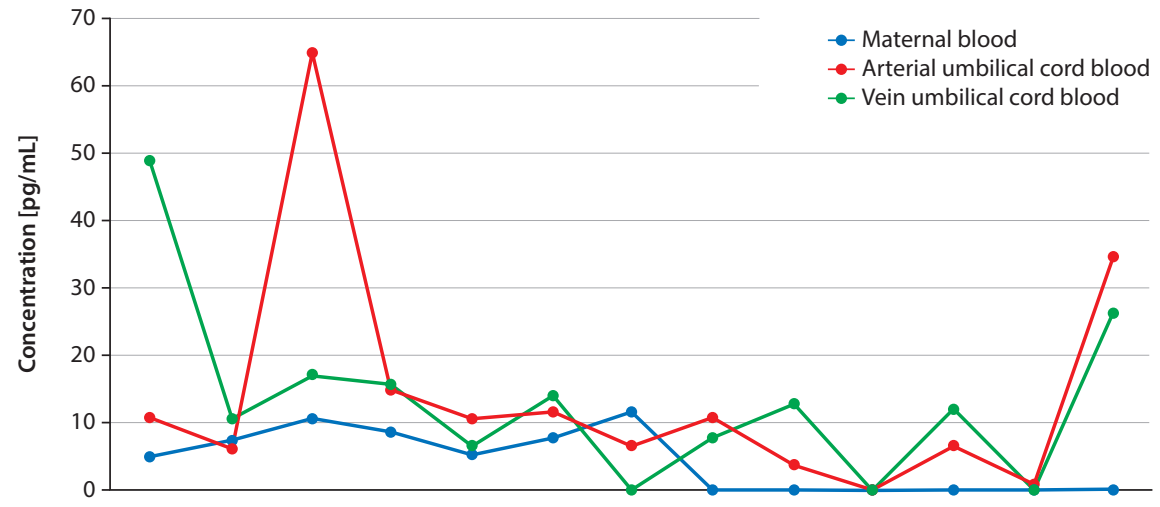

Figure 8. Survivin concentration in compared blood samples

The results obtained from cord blood vein is presented in Figure 7.

The highest Survivin concentration from umbilical cord vein serum was $49.28 \mathrm{pg} / \mathrm{mL}$. In 6 cases where the results in maternal blood were nearly negative we found 3 negative results. Mean value of Survivin was $13.16 \mathrm{pg} / \mathrm{mL}$ (sd. 13.3).

The results of Survivin concentrations obtained from maternal blood and cord blood are compared and presented in Figure 8.
By comparing differences betveen Survivin in plasma concentrations from maternal blood and cord blood — from arteries and vein done by ANOVA variancy analysis, no statistical differences were found.

Post-hoc analysis shows no statistical differences between compared samples of Survivin ( $p>0.05$ ).

The mean concentrations of Survivin were similar but we found that in some cases the results in cord blood serum in both vessels-vein and arteries were almost negative. Arterial 
values of Survivin in umbilical cord compared to maternal blood were higher, but no statistical difference was found.

\section{DISCUSSION}

TIMP-1 is known as an active inhibitor of matrix proteases and as a growth-promoting factor. Serum concentration of TIMP-1 was to our knowledge not yet measured in pregnant women during 3-rd trimester of pregnancy and compared to vein and arterial cord blood. We expected to find out the possible differences between maternal and fetal blood. The hypothesis that the distribution of serum TIMP-1 in fetal umbilical cord vein and artery could differ due to changes that may occur in placental structures was promising. We did not find any statistical differences between TIMP-1 concentration in arterial and vein umbilical blood. Comparing fetal and maternal serum concentration of TIMP-1 we observed no differences either. The source of TIMP-1 in serum due to observation of Lee and al. [12]. could be caused by peripheral $\mathrm{T}$ cell activation, as found it in multiple sclerosis. Authors pointed that TIMP-1 could be elevated in different conditions related to inflammatory processes and probably in our study inflammation process did not occur.

In two cases in maternal blood the concentration was high [> $300 \mathrm{ng} / \mathrm{mL}$ ] in comparison with the results of Ylisirnio, but more often we saw high concentration of TIMP-1 in fetal cord blood [4 cases]. In cancer high level of TIMP-1 is correlated to bad prognosis, but we still don't know what impact for high TIMP-1 concentration for pregnancy is [13]. The concentration of TIMP-1 in maternal sera was lower than in the group of healthy patients of both gender - as was presented in article of Holten-Andersen M. [14].

The statistical analysis of other authors shows that the level of TIMP-1 protein in the sera of patients is correlated with gender. The serum of male patients compared with its concentration in female counterparts was significantly lower level of theTIMP-1 [15].

The presence of lower levels of TIMP-1 in pregnancy observed in cases of cancer could be explained by a lack of poor differentiation of cells and the presence of mature cells. Our observations confirm the results of the research conducted by Giaginis [16].

We exclude inflammatory processes in our study knowing that chorioamnionitis as an inflammatory process is correlated with an elevated tissue inhibitor of metalloproteinase 1 levels [17]. As Tency noticed TIMP-1 concentrations were lower in preterm gestation, irrespective of labor [18].

There is no difference between mean concentrations of TIMP-1 comparing vein and artery of umbilical cord blood that could suggest no inflammatory processes presence and no proliferation in placental circulation.
The second measured molecule was Survivin, that plays a regulative role in placental development. Changes of Survivin concentration in early pregnancy could lead to placental dysfunction and complications in pregnancy development later.

In our study mean concentrations of Survivin in maternal blood and in cord blood serum in both vessels-vein and arteries were similar but we found that in some cases in both umbilical cord vessels the results were negative. Arterial values of Survivin in umbilical cord compared to maternal blood were higher, but no statistical difference was found.

In Matamitsi-Puchner study no statistically significant differences in Survivin concentrations in cord blood were observed between IUGR, LGA and AGA groups, but the results were obtained from mixed blood. Birth weight, customized centile, gestational age, gender of neonate, mode of delivery and parity influence on Survivin concentrations was not found [19]. This study showed that Survivin concentrations in cord blood probably do not reflect the disturbances of feto-placental apoptosis, expected in IUGR and fetal macrosomia, due to gestational DM.

Our results of Survivin concentration in cord blood separately for vein and artery could be useful to establish reference values for full-term neonates as Malamitsi-Puchner suggested in her publication [19]. The continuation of analysis and additional studies, reporting the concentration of survivin in cord blood in different pregnancy complications are required to answer the question how abnormal placentation process could have impact on pregnancy development.

\section{CONCLUSIONS}

In III-rd trimester of pregnancy parameters of Timp-1 and Survivin - anti-apoptotic substances concentration were similar in maternal and cord blood in both artery and vein. We found no increased activity of selected antiapoptotic factors. The study should be continued in larger group of patients.

\section{REFERENCES}

1. Bonnema DD, Webb CS, Pennington WR, et al. Effects of age on plasma matrix metalloproteinases (MMPs) and tissue inhibitor of metalloproteinases (TIMPs). J Card Fail. 2007; 13(7): 530-540, doi: 10.1016/j. cardfail.2007.04.010, indexed in Pubmed: 17826643.

2. Divya S, Sanjeev S, Tapas KC. Multifaceted role of matrix metalloproteinases (MMPs). Front Mol Biosci. 2015; 2: 19-23.

3. Hu J, Van den Steen PE, Sang QXA, et al. Matrix metalloproteinase inhibitors as therapy for inflammatory and vascular diseases. Nat Rev Drug Discov. 2007; 6(6): 480-498, doi: 10.1038/nrd2308, indexed in Pubmed: 17541420.

4. Candelario-Jalil E, Yang Y, Rosenberg GA. Diverse roles of matrix metalloproteinases and tissue inhibitors of metalloproteinases in neuroinflammation and cerebral ischemia. Neuroscience. 2009; 158(3): 983-994, doi: 10.1016/j.neuroscience.2008.06.025, indexed in Pubmed: 18621108.

5. Koskivirta I, Rahkonen $O$, Mäyränpää $M$, et al. Tissue inhibitor of metalloproteinases 4 (TIMP4) is involved in inflammatory processes of human cardiovascular pathology. Histochem Cell Biol. 2006; 126(3): 335-342, doi: 10.1007/s00418-006-0163-8, indexed in Pubmed: 16521002. 
6. Higa R, Kurtz M, Capobianco E, et al. Altered matrix metalloproteinases and tissue inhibitors of metalloproteinases in embryos from diabetic rats during early organogenesis. Reprod Toxicol. 2011; 32(4): 449-462, doi: 10.1016/j.reprotox.2011.09.003, indexed in Pubmed: 21963884.

7. Świerczewski A, Kobos J, Pasiński J, et al. Ekspresja metaloproteinazy MMP-9 oraz tkankowego inhibitora metaloproteinazy TIMP-2 w łożyskach u ciężarnych z wewnątrzmacicznym ograniczeniem wzrastania płodu. Ginekol Pol. 2012; 83: 439-45.

8. Seval Y, Akkoyunlu G, Demir R, et al. Distribution patterns of matrix metalloproteinase (MMP)-2 and -9 and their inhibitors (TIMP-1 and TIMP-2) in the human decidua during early pregnancy. Acta Histochem. 2004; 106(5): 353-362, doi: 10.1016/j.acthis.2004.07.005, indexed in Pubmed: 15530550.

9. Tamm I, Richter S, Oltersdorf D, et al. High expression levels of $\mathrm{x}$-linked inhibitor of apoptosis protein and survivin correlate with poor overall survival in childhood de novo acute myeloid leukemia. Clin Cancer Res. 2004; 10(11): 3737-3744, doi: 10.1158/1078-0432.CCR-03-0642, indexed in Pubmed: 15173080.

10. Doucette $T$, Latha $K$, Yang $Y$, et al. Survivin transcript variant 2 drives angiogenesis and malignant progression in proneural gliomas. Neuro Oncol. 2014; 16(9): 1220-1228, doi: 10.1093/neuonc/nou034, indexed in Pubmed: 24676140.

11. Xu P,Wang Y, Piao Y, et al. Effects of matrix proteins on the expression of matrix metalloproteinase-2,-9, and -14 and tissue inhibitors of metalloproteinases in human cytotrophoblast cells during the first trimester. Biol Reprod. 2001; 65(1): 240-246, indexed in Pubmed: 11420245.

12. Lee MA, Palace J, Stabler G, et al. Serum gelatinase B, TIMP-1 and TIMP-2 levels in multiple sclerosis. A longitudinal clinical and MRI study. Brain. 1999; 122 ( Pt 2): 191-197, indexed in Pubmed: 10071048.
13. Ylisirniö $S$, Höyhtyä $M$, Turpeenniemi-Hujanen T. Serum matrix metalloproteinases $-2,-9$ and tissue inhibitors of metalloproteinases $-1,-2$ in lung cancer--TIMP-1 as a prognostic marker. Anticancer Res. 2000; 20(2B): 1311-1316, indexed in Pubmed: 10810441.

14. Holten-Andersen M, Christensen IJ, Nilbert M, et al. EORTC-Receptor and Biomarker Group. Association between preoperative plasma levels of tissue inhibitor of metalloproteinases 1 and rectal cancer patient survival. a validation study. Eur J Cancer. 2004; 40(1): 64-72, indexed in Pubmed: 14687791.

15. Niewiarowska K, Pryczynicz A, Dymicka-Piekarska V, et al. Diagnostic significance of TIMP-1 level in serum and its immunohistochemical expression in colorectal cancer patients. Pol J Pathol. 2014; 65(4): 296-304, indexed in Pubmed: 25693084.

16. Giaginis C, Nikiteas N, Margeli A, et al. Serum tissue inhibitor of metalloproteinase 1 and 2 (TIMP-1 and TIMP-2) levels in colorectal cancer patients: associations with clinicopathological variables and patient survival. Int J Biol Markers. 2009; 24(4): 245-252, indexed in Pubmed: 20108216.

17. Locksmith GJ, Clark P, Duff P, et al. Amniotic fluid concentrations of matrix metalloproteinase 9 and tissue inhibitor of metalloproteinase 1 during pregnancy and labor. Am J Obstet Gynecol. 2001; 184(2): 159-164, doi: 10.1067/mob.2001.108860, indexed in Pubmed: 11174496.

18. Tency I, Verstraelen $\mathrm{H}$, Kroes I, et al. Imbalances between matrix metalloproteinases (MMPs) and tissue inhibitor of metalloproteinases (TIMPs) in maternal serum during preterm labor. PLoS One. 2012; 7(11): e49042, doi: 10.1371/journal.pone.0049042, indexed in Pubmed: 23145060.

19. Malamitsi-Puchner A, Baka S, Boutsikou M, et al. Cord blood survivin concentrations in human full-term normal and complicated pregnancies. In Vivo. 2009; 23(1): 139-142, indexed in Pubmed: 19368138. 